\title{
Casebook of a Community Internist: Fun with Finals
}

\author{
Hector M Baillie
}

Hector Baillie is a General Internist in Nanaimo, BC and the founding editor of the Canadian Journal of General Internal Medicine. Author for correspondence: Hector M. Baillie: hbaillie@telus.net Received: 9 June 2020; Accepted after revision: 11 June 2020; Published: 26 March 2021.

DOI: http://dx.doi.org/10.22374/cjgim.v16il.468

Since the days of intense studying and examination, a lot of water has passed under the proverbial bridge. However, I remember my Undergraduate Finals to this day.

At Glasgow University, there were 4 Oral Exams (Medicine, Pediatrics, Surgery and OBGyn) at the end of year 5. You didn't fail these exams and come away unscathed. And they brought REAL patients in from the community - no acting here.

I remember my Surgical Final exam. I was assigned a patient to interview and examine, and then I met with my examiners. Professor Sir Andrew Watt Kay was an impressive man, and I actually did some training on his wards. Professor George Eddington was 'the external examiner', the unknown quantity or fear-factor before the Americans invented it. As I entered the room, Prof Kay excused himself (a phone call, pee-break, or something equally unbelievable), and I was left facing my fate with a stranger. "What did you learn from Mr. Robertson?" he said, and I rattled off my summary. A 28-year-old man with a teratoma of the testis. "And why is he of surgical interest?" I recalled that such patients would come in for a staging laparotomy, a splenectomy, a wedge biopsy of the liver, and (in women) to have ovaries tied in the midline in case irradiation was necessary. So far, so good "And what advice would you give him?" he asked. In retrospect, he was fishing for my knowledge of sperm banking if he wanted to be a dad. I said, "Well, last year I won 10 pounds on the Grand National". There was a pause, a downward gaze, and some loss of train-of-thought. $\mathrm{He}$ looked up, and with a piercing gaze and furrowed brows, growled, "Do explain, young man." I told him that Bob Champion had been diagnosed with teratoma testis, was given chemotherapy, and the following year rode Aldaniti to win the Grand National.

There was an awkward silence. I thought, "Oh God, what have I done?" He indicated the interview was over and ushered me out. No reassuring words, no handshake, just goodbye. A week went by before the results of the Finals were posted in the University Quadrangle noticeboard - 'Baillie, pass. Distinction
Oral'. My heart sank. Whilst all my mates were drinking heavily in celebration, I was studying aspects of Surgery that really weren't my forte. This time, Professor Anderson was up to the task. "Tell me all you know about the classification and subclassification of portal hypertension." Shortest exam I ever sat.

My Pediatrics Final was almost as exciting. The child I was asked to examine was 9 years old. He suffered from tremor, rigidity, and akinesia. I had brought candy with me just in case he wasn't going to co-operate: he proved to be pragmatic and bribable. Unfortunately, he wasn't able to answer key questions pertaining to the etiology of his Parkinsonian condition. Professor Collins peered over his glasses, agreed with my clinical assessment, and asked the obvious question - "Why?" Of course, I threw up the disease states I associated with paralysis agitans, including encephalitis lethargica, MPTP-heroin, manganese, carbon monoxide poisoning, and trauma. Pretty unlikely, though, given the circumstances. He pressed me to continue, goading my frontal lobes and my basal ganglia. And then I remembered - he had brown eyes! Could his iris discolouration could be the Kayser-Fleisher rings associated with Wilson's disease? Copper deposition was possible not only in the eye but the liver and the basal ganglia. "Ah-ha!" he said, obviously impressed that his train of enquiry was leading somewhere. He took a deep breath in, grinned from ear to ear, and said exhaled gleefully “... no". I admitted defeat. He picked up the chart, turned to page 1, and asked, "how was he born?" "Breech" I replied. The process of anoxic insult was self-evident. Don't tell me I was crashing Pediatrics!

We moved over to meet a young child, maybe 3 , whose eyebrows met in the midline. She had some finger deformities too. "What's going on here?" I was asked. The only person I knew with eyebrows like this was Freda Khalo, the Mexican artist and communist activist. "Some sort of genetic condition, maybe with some hypothyroidism thrown in?". He smiled, and said "Have you not heard of an Amsterdam Dwarf?" My confidence began to wane. 
The X-rays were next. A fractured humerus in an infant (but oriented vertically, which made me consider the tiny bone to be a femur): an IVP of left-sided hydronephrosis, but displayed backto-front, thereby tricking the unwary of which kidney was affected: and an $\mathrm{x}$-ray of a baby on its head, with contrast being trickled into the rectum (an invertogram, for rectal atresia). This was the last straw: I was disappointed, disillusioned and now disoriented. That night I considered a future in Law. For the first time, I felt sorry for Nick Morrison, the barely-passing student who revelled with 51\%. His day was going to be a bloody nightmare.

In my Internal Medicine Orals, I fared better. This was Canada, right? The long case was a 59-year-old man with finger clubbing, and wearing oxygen. He greeted me with, "don't worry, it's not cancer." Velcro crackles confirmed the diagnosis, and I spent the next hour talking about his summer holiday and boat-building. The short case wasn't so easy. A 67-year-old man with a 'dry mouth'. And neuropathy, hepatosplenomegaly, and proteinuria. I learned more in the next hour about AA-amyloidosis than I will ever use in my career. Thankfully, he was a good teacher. My examiners were impressed by my diagnostic skill and ability to predict the potential success or failure of various treatment options. Thanks, Mike.

What did this experience teach me? Humility? My wife would argue against this. But when I did a spell as a Royal College examiner, I was anxious to be kind and cognizant of the stress of the event. And I never forgot what patients (and their predicaments) could - and still do - teach me. 